\title{
Preimplantation genetic diagnosis (PGD) for Huntington's disease: the experience of three European centres
}

\author{
Maartje C Van Rij ${ }^{1,5}$, Marjan De Rademaeker ${ }^{2,5}$, Céline Moutou ${ }^{3,5}$, Jos CFM Dreesen ${ }^{1}$, Martine De Rycke ${ }^{2}$, \\ Inge Liebaers ${ }^{2}$, Joep PM Geraedts ${ }^{1}$, Christine EM De Die-Smulders ${ }^{\star, 1}$ and Stéphane Viville ${ }^{3,4}$ on behalf of the \\ BruMaStra PGD working group
}

This study provides an overview of 13 years of experience of preimplantation genetic diagnosis (PGD) for Huntington's disease (HD) at three European PGD centres in Brussels, Maastricht and Strasbourg. Information on all 331 PGD intakes for HD, couples' reproductive history, PGD approach, treatment cycles and outcomes between 1995 and 2008 were collected prospectively. Of 331 couples for intake, $68 \%$ requested direct testing and $32 \%$ exclusion testing (with a preponderance of French couples). At the time of PGD intake, $39 \%$ of women had experienced one or more pregnancies. A history of pregnancy termination after prenatal diagnosis was observed more frequently in the direct testing group $(25 \%)$ than in the exclusion group (10\%; $P=0.0027)$. PGD workup was based on two approaches: (1) direct testing of the CAG-triplet repeat and (2) linkage analysis using intragenic or flanking microsatellite markers of the HTT gene. In total, 257 couples had started workup and 174 couples (70\% direct testing, $30 \%$ exclusion testing) completed at least one PGD cycle. In total, 389 cycles continued to oocyte retrieval (OR). The delivery rates per OR were $19.8 \%$, and per embryo transfer $24.8 \%$, resulting in 77 deliveries and the birth of 90 children. We conclude that PGD is a valuable and safe reproductive option for HD carriers and couples at risk of transmitting HD.

European Journal of Human Genetics (2012) 20, 368-375; doi:10.1038/ejhg.2011.202; published online 9 November 2011

Keywords: preimplantation genetic diagnosis (PGD); Huntington's disease (HD); HTT gene; exclusion testing; delivery rates; prenatal diagnosis

\section{INTRODUCTION}

Huntington's disease (HD; MIM: 143100) is a progressive neurodegenerative disorder seriously affecting the quality of life of patients and their families. Clinical signs are progressive motor disability featuring chorea, as well as mental disturbances such as cognitive decline, changes in personality and depression. ${ }^{1}$ The mean age of onset is 35 to 44 years and the median survival time is 15 to 18 years after onset. ${ }^{2-4}$ In populations of western European descent, the prevalence varies between 5 and 10 per $100000 .^{3,4}$

The disease-causing mutation is an expanded CAG repeat sequence in exon 1 of the HTT gene (ref. seq NM002111.6) on chromosome 4 (4p16.3), transmitted as an autosomal dominant trait. ${ }^{2}$ HD is fully penetrant in patients having $\geq 40$ CAG repeats; 36-39 CAG repeats are associated with reduced penetrance, whereas $27-35$ repeats are within the intermediate range. Intermediate repeats are not penetrant, but may lead to expansion if transmitted to offspring.

Reproductive options for gene carriers or at-risk persons include prenatal diagnosis (PND) and preimplantation genetic diagnosis (PGD).$^{5-8}$ For confirmed carriers, PGD can provide direct testing of embryos obtained after in vitro fertilisation (IVF) via an intracyto- plasmic sperm injection (ICSI). The CAG repeat length is tested in one or two blastomeres from each embryo, and, if available, one or two unaffected embryos are selectively transferred into the uterus. ${ }^{7}$

At-risk persons who prefer to be uninformed about their HD carrier status, and do not wish to undergo presymptomatic testing, can be offered exclusion testing either by PND or PGD. The exclusion test is based on identifying the grandparental origin of the two HTT alleles. ${ }^{9}$ If one of the two alleles from the affected grandparent is found in the fetus after exclusion PND, a termination of pregnancy (TOP) is offered, although the fetus only has a $50 \%$ risk of being a carrier of the CAG expansion. In exclusion PGD, only embryos with one of the two HTT alleles from the non-affected grandparent are transferred. ${ }^{6}$ Both the availability and cooperation of family members in providing a sample for PGD workup is necessary for exclusion testing.

An alternative method for those who do not want to know their carrier status is non-disclosure PGD. ${ }^{10}$ Embryos are analysed directly for a CAG repeat, without any details of PGD results being revealed to patients. Only embryos without an expansion are transferred. ${ }^{11}$ Non-disclosure PGD remains controversial and has been rejected by many PGD centres. $5,6,12,13$

\footnotetext{
${ }^{1}$ Department of Clinical Genetics, Maastricht University Medical Centre, Maastricht, The Netherlands; ${ }^{2}$ Centre for Medical Genetics, Universitair Ziekenhuis Brussel, Brussels, Belgium; ${ }^{3}$ Service de Biologie de la Reproduction, Centre Hospitalier Universitaire, Strasbourg, France; ${ }^{4}$ Institut de Génétique et de Biologie Moléculaire et Cellulaire (IGBMC), Institut National de Santé et de Recherche Médicale (INSERM) U964/Centre National de Recherche Scientifique (CNRS) UMR 1704/Université de Strasbourg, IIIkirch, France *Correspondence: Dr CEM De Die-Smulders, Department of Clinical Genetics, Maastricht University Medical Centre, Postbus 5800 , 6202 AZ Maastricht, The Netherlands. Tel: +31 43 3877855; Fax: +31 43 3875800; E-mail: c.dedie@mumc.nl

5 Joint first author.

Received 13 April 2011; revised 5 September 2011; accepted 15 September 2011; published online 9 November 2011
} 
The PGD centres in Brussels (Belgium), Maastricht (The Netherlands) and Strasbourg (France) offer PGD for HD. We provide an overview of our experience of PGD for HD between 1995 and 2008. Our aims are as follows: (1) to provide a comparative overview of PGD approaches and technical workup in the three centres, (2) to study differences in the populations who apply for PGD and their reproductive histories, (3) to compare PGD results in the three centres, as well as to compare them with literature data.

\section{PATIENTS AND METHODS}

The data on all intakes, cycles and outcomes of PGD treatment for HD in the PGD centres in Brussels, Maastricht and Strasbourg from 1995 to 2008 were prospectively collected.

\section{Patients and counselling}

A total of 331 couples obtained genetic and reproductive counselling by a clinical geneticist before being referred for PGD. The PGD intakes were performed by a clinical geneticist, a gynaecologist and/or a PGD co-worker either at the outpatient clinic (Brussels, Maastricht) or by telephone (Strasbourg). Couples were provided with verbal and written information on IVF and ICSI, the single-cell diagnostic procedure, the success rates of the IVF/PGD treatment and the small risk of misdiagnosis. ${ }^{14,15}$ The advantages and disadvantages of PGD in comparison with relevant alternative reproduction options were discussed. Informed consent was given by both partners before treatment. The reproductive history concerning fertility problems, previous pregnancies with or without PND and/or TOP, and the number of living children was noted. Couples had to be suitable candidates for IVF/ PGD according to the European Society of Human Reproduction and Embryology (ESHRE) IVF and PGD guidelines. ${ }^{16,17}$ Reasons for being rejected by the PGD centre were recorded, as well as reasons for couples refraining from PGD if this information was available. If symptoms of HD were observed during intake (Brussels or Maastricht), a neurologist and a psychologist were consulted, and the PGD request was evaluated by the local PGD team and occasionally the ethics committee. In general, it is considered that assisted reproduction technology involves shared responsibility for parental caregivers and health-care providers in respect of a prospective child. If a couple does not seem to be able to provide a stable environment in which the child will grow up, the couple can be rejected for PGD.

\section{PGD workup}

The PCR single-cell protocols applied in this study are based on two approaches: (1) direct testing of the (CAG)n triplet repeat, and (2) linkage analysis using one or more intragenic or flanking microsatellite markers, in addition to the direct approach or for exclusion testing (Table 1). ${ }^{5-8}$

\section{Ovarian stimulation and oocyte retrieval}

Controlled ovarian hyperstimulation was carried out in a GnRH agonist or antagonist protocol. PGD treatment requires a higher minimum follicle count for oocyte retrieval (OR) than regular IVF treatment, as relatively more embryos are 'lost' during the PGD procure (rejected for being affected/at risk). The minimum follicle count for OR was four for Maastricht and six for Strasbourg. In Brussels, the preferred minimum follicle count for OR was nine, the exact number, however, being established on an individual basis. ${ }^{18}$

\section{ICSI and embryo biopsy procedure}

IVF with ICSI was carried out as described previously. ${ }^{19}$ After careful assessment of the embryo's development, blastomere biopsy was carried out on day 3. Depending on the total number of embryonic cells and the PGD approach, one or two blastomeres were removed by making a hole in the zona pellucida with a stream of acid Tyrode's solution or with a laser. ${ }^{20-22}$

\section{PGD approach}

Single-cell testing methods were very similar in the three PGD centres (Table 1). After biopsy, blastomeres were washed and tubed in alkaline lysis buffer with $\mathrm{KOH}$ or $\mathrm{NaOH}$ and maintained at -20 or $-80^{\circ} \mathrm{C}$ for at least $30 \mathrm{~min}$. A blank control was made for each blastomere, as recommended by the PGD best practice guidelines at the time. ${ }^{17}$ Samples were lysed at $65^{\circ} \mathrm{C}$ for $10 \mathrm{~min}$, before the addition of PCR reaction components.

Initially, PCR reactions were based on simplex PCR. Later, multiplex fluorescent PCR was introduced, which allowed simultaneous amplification of two to six loci.

Table 1 Strategies in use for PGD for Huntington disease in the BruMaStra PGD centres

\begin{tabular}{|c|c|c|c|}
\hline & Brussels & Maastricht & Strasbourg \\
\hline Direct testing & $(\mathrm{CAG}) \mathrm{n}$ or $(\mathrm{CAG}) \mathrm{n}+\mathrm{IVS} 1 \mathrm{CA}$ & $(C A G) n$ & (CAG)n+D4S127+ D4S412+IVS1CA \\
\hline $\begin{array}{l}\text { Direct testing (if not } \\
\text { informative for (CAG)n) }\end{array}$ & $(C A G) n+I V S 1 C A$ & $\begin{array}{l}\text { D4S1614+D4S127+D4S3034+ } \\
\text { D4S412 }\end{array}$ & $(\mathrm{CAG}) \mathrm{n}+\mathrm{D} 4 \mathrm{~S} 127+\mathrm{D} 4 \mathrm{~S} 412+\mathrm{IVS} 1 \mathrm{CA}$ \\
\hline Exclusion testing & IVS1CA + D4S127 & $\begin{array}{l}\text { D4S1614+D4S127+D4S3034+ } \\
\text { D4S412 }\end{array}$ & $\begin{array}{l}\text { D4S3038+D4S1614+D4S127+IVS1CA+ } \\
\text { D4S3034+D4S412 }\end{array}$ \\
\hline $\begin{array}{l}\text { Alkaline lysis buffer } \\
\text { (ALB) }\end{array}$ & $\begin{array}{l}50 \mathrm{~mm} \text { DTT, } 200 \mathrm{~mm} \mathrm{NaOH} \text { or } 50 \mathrm{~mm} \text { DTT, } \\
200 \mathrm{~mm} \mathrm{KOH}\end{array}$ & 50 mм DTT, 200 mм NaOH & 50 mм DTT, 200 mм KOH \\
\hline Freezing post tubing & ${ }^{3} 30^{\prime}-20^{\circ} \mathrm{C}$ & ${ }^{3} 30^{\prime}-20^{\circ} \mathrm{C}$ & ${ }^{3} 30^{\prime}-20^{\circ} \mathrm{C}$ \\
\hline Decontamination & UV-C and/or restriction enzyme & UV-C and/or restriction enzyme & UV-C \\
\hline Polymerase & $\begin{array}{l}\text { Taq Polymerase (Perkin Elmer, Waltham, } \\
\text { MA, USA) (CAG)n } \\
\text { Expand Long Template PCR system (Roche } \\
\text { Diagnostics, Basel, Switzerland): duplex }\end{array}$ & $\begin{array}{l}\text { Expand Long Template PCR system (Roche Diagnostics, } \\
\text { Basel, Switzerland): (CAG)n } \\
\text { Expand High Fidelity PCR system (Roche Diagnostics, } \\
\text { Basel, Switzerland): linkage }\end{array}$ & $\begin{array}{l}\text { Qiagen Multiplex PCR KIT (Qiagen, } \\
\text { Düsseldorf, Germany) }\end{array}$ \\
\hline Split for multiplex PCR & Yes & No & No \\
\hline Genetic analyser & $\begin{array}{l}\text { ALF } \\
A B I 3100\end{array}$ & $\begin{array}{l}A B \mid 377 \\
A B I 3100 \\
A B I 3730\end{array}$ & ABI 3100 \\
\hline
\end{tabular}


Embryo transfer, pregnancy outcome and children

One or two unaffected embryos were transferred into the uterus on days 3 to 5 post insemination. The age of the woman, number of unsuccessful previous attempts and embryo quality determined the number of embryos to be transferred. For Belgian patients, the reimbursement policy of July 2003 required a selective single-embryo transfer in patients aged $\leq 36$ years. Supernumerary unaffected embryos of good morphology were cryopreserved. ${ }^{23}$ Biochemical pregnancy was confirmed when serum or urine beta hCG concentrations showed an increase at least 10 days after transfer. Clinical pregnancy was recorded when a gestational sac was seen on ultrasound at least 4 weeks after embryo transfer. Ongoing pregnancy was registered if ultrasound showed a fetal heartbeat at $\geq 12$ weeks of gestational age. Loss of a fetus or gestational sac $\leq 20$ weeks were recorded as a miscarriage. ${ }^{24}$

The option of a control PND by CVS or amniocentesis was offered to pregnant women. Data on children born were collected through questionnaires addressed to the parents and their gynaecologists. In Brussels, children were examined whenever possible by a trained paediatrician. $^{25}$

\section{Legal aspects}

PGD for HD based on direct testing is allowed in all three centres. In Belgium, PGD practice has been regulated by law since $2007 .{ }^{26}$ Direct testing was first applied in 1997. ${ }^{7}$ Exclusion testing has been offered since 2000, whereas non-disclosure PGD was rejected after thorough discussion. ${ }^{6}$ In the Netherlands, PGD for direct HD testing has been allowed since 1998, following the directive relating to similar indications for PND and PGD. The first HD test was applied in 1999. In 2002, an embryo law was introduced, which was similar to the one in Belgium. Although HD exclusion testing remains accepted in PND,
HD exclusion testing and HD non-disclosure testing has been excluded for PGD since 2006. ${ }^{27}$ The Maastricht PGD centre is the only certified PGD centre in the Netherlands. In France, specific PGD legislation was introduced in 2000, defining PGD as an ultraprecocious form of PND. Initially, exclusion PGD was not permitted until the law was revised in 2004. PGD can only be practised in centres licensed by the Agence de Biomedecine. Similar to PGD requests, PND requests for HD have to be presented to a local multidisciplinary commission. However, exclusion PND for HD is exceptional, as most local multidisciplinary commissions do not accept TOP of at-risk fetuses and consider PGD as a better solution. Since exclusion PGD has been introduced, exclusion PND is no longer offered in France.

\section{Reimbursement of PGD}

In Belgium, PGD costs for Belgian couples are covered by their health insurance for six cycles, provided embryo transfer rules are respected. The Dutch health insurance companies cover three IVF/PGD cycles. In France, the cost of four IVF/PGD cycles resulting in embryo transfer are covered by the national health system.

\section{Statistical analyses}

The differences between the centres relating to frequencies within the study populations were calculated using a $\chi^{2}$-test. The mean age of woman at treatment was compared with ANOVA.

\section{RESULTS}

\section{Patients and counselling}

In total, 331 couples had a PGD intake at one of the three centres (Table 2), 68\% of couples (225/331) requested direct testing and $32 \%$ (106/331) requested exclusion PGD. In Strasbourg, significantly more

Table 2 PGD intakes for HD per BruMaStra PGD centre (1995-2008)

\begin{tabular}{|c|c|c|c|c|c|c|c|c|c|c|c|c|}
\hline \multirow[b]{2}{*}{ Methods } & \multicolumn{3}{|c|}{ Brussels } & \multicolumn{3}{|c|}{ Maastricht } & \multicolumn{3}{|c|}{ Strasbourg } & \multicolumn{3}{|c|}{ Total } \\
\hline & Direct & Exclusion & Total & Direct & Exclusion & Total & Direct & Exclusion & Total & Direct & Exclusion & Total \\
\hline Couples for intake & 78 & 38 & 116 & 91 & 9 & 100 & 56 & 59 & 115 & 225 & 106 & 331 \\
\hline \multicolumn{13}{|l|}{ At-risk person } \\
\hline Male & 46 & 16 & 62 & 37 & 3 & 43 & 28 & 34 & 62 & 111 & 56 & 167 \\
\hline Female & 32 & 22 & 54 & 54 & 6 & 57 & 28 & 25 & 53 & 114 & 50 & 164 \\
\hline \multicolumn{13}{|l|}{ CAG repeat length HD carrier } \\
\hline 36-39 & 3 & & & 6 & & & 6 & & & 15 & & \\
\hline$>40$ & 67 & & & 66 & & & 41 & & & 174 & & \\
\hline Unknown/not tested & 8 & & & 19 & & & 9 & & & 36 & & \\
\hline \multicolumn{13}{|l|}{ Couples' reproductive history } \\
\hline Infertility & 6 & 6 & 12 & 13 & 1 & 14 & 11 & 3 & 14 & 30 & 10 & 40 \\
\hline$\geq 1$ Pregnancy & 29 & 20 & 49 & 37 & 4 & 41 & 26 & 13 & 39 & 92 & 37 & 129 \\
\hline$\geq 1$ TOP after PND & 18 & 8 & 26 & 22 & 2 & 24 & 17 & 1 & 18 & 57 & 11 & 68 \\
\hline$\geq 1$ TOP without PND & & 1 & 1 & 1 & & 1 & 4 & 4 & 8 & 5 & 5 & 10 \\
\hline$\geq 1$ Child (with or without PND) & 18 & 4 & 22 & 17 & 2 & 19 & 12 & 7 & 19 & 47 & 13 & 60 \\
\hline Total no. of children & 18 & 5 & 23 & 18 & 2 & 20 & 14 & 8 & 22 & 50 & 15 & 65 \\
\hline PND excluded HD (risk) & 11 & 3 & 14 & 10 & & 10 & 4 & 0 & 4 & 25 & 3 & 28 \\
\hline PGD excluded HD & 1 & & 1 & & & & & & & 1 & 0 & 1 \\
\hline Ongoing pregnancy after affected PND & & & & 1 & & 1 & & & & 1 & 0 & 1 \\
\hline No test performed & 6 & 2 & 8 & 7 & 2 & 9 & 10 & 8 & 18 & 23 & 12 & 35 \\
\hline Family risk unknown & 4 & 1 & 5 & 5 & & 5 & 6 & 1 & 7 & 15 & 2 & 17 \\
\hline HD risk known & & & & 2 & 2 & 4 & & 2 & 2 & 2 & 4 & 6 \\
\hline Other relation & 1 & 1 & 2 & & & & & 1 & 1 & 1 & 2 & 3 \\
\hline Reason unknown & 1 & & 1 & & & & 4 & 4 & 8 & 5 & 4 & 9 \\
\hline
\end{tabular}

Abbreviations: HD, Huntington disease; PND, prenatal diagnosis; PGD, preimplantation genetic diagnosis; TOP, termination of pregnancy. 
couples asked for exclusion testing compared with Brussels (direct $v s$ exclusion 49:51\% for Strasbourg and 67:33\% for Brussels; difference between these centres $P=0.0065)$. In Brussels, 71 of 116 intakes were Belgian couples, the remaining were couples from abroad, mainly from Germany. In Maastricht, all couples were Dutch. In Strasbourg, the vast majority of the couples were French.

The male:female ratio of carriers/at-risk persons for the three centres was 1:1.03 (111:114) for direct testing, and 1:0.89 (56:50) for exclusion testing, showing no significant skewing. In the direct testing group, $8.6 \%(15 / 174)$ of the carriers had an allele with a reduced penetrance. The mean age of woman at intake was 29.64 years. No significant age difference was seen between the centres and between direct and exclusion testing (data not further shown).

\section{Reproductive history}

Fertility problems necessitating IVF/ICSI were reported in $12 \%$ $(40 / 331)$ of the couples (Table 2). Of the total number of intakes, $39 \%$ (129/331) of women had $\geq 1$ previous pregnancy and $21 \%$ (68/331) had experienced $\geq 1$ TOP after PND for HD. Significantly more women in the direct testing group had experienced TOP $(25 \%, 57 /$ $225)$ compared with the exclusion group (10\% (11/106); $P=0.0027)$.

For the exclusion group, more couples in Brussels (53\%, 20/38) than in Strasbourg $(22 \%, 13 / 59)$ had had at least one previous pregnancy $(P=0.007)$. In Brussels, $21 \%(8 / 38)$ of the couples had a history of $\geq 1$ TOP after exclusion PND, whereas in Strasbourg there was only one TOP after PND in the exclusion group $(P=0.0045)$. In Strasbourg, eight couples had a TOP without PND compared with one in Maastricht and one in Brussels.

A total of $18 \%(60 / 331)$ of the couples had at least one living child. Relatively, more couples in the direct testing $(21 \%, 47 / 225)$ had offspring $(P=0.08)$ than in the exclusion group $(12 \%, 13 / 106)$. In $45 \%(29 / 65)$ of these children, the risk of HD was excluded by direct testing $(52 \%, 26 / 50)$ or exclusion testing $(20 \%, 3 / 15)$. either. However, the differences were not significant $(P=0.059)$.

HD was excluded by PND or PGD in 65\% (15/23) of previous children from couples in Brussels, 50\% (10/20) in Maastricht and 18\% (4/22) in Strasbourg ( $P=0.0055$, difference between three centres). One of the couples referred for PGD in Maastricht had continued an affected pregnancy. In 17 out of 35 untested children, the (family) risk of HD was not yet known at the time of the pregnancy (Table 2).

\section{Genetic workup and outcomes after PGD intake}

Couples' genetic workup and outcomes after intake are shown in Table 3. For $78 \%$ (257/331) of the couples, genetic workup was started: $81 \%(183 / 225)$ for direct testing and 70\% (74/106) for exclusion testing. In Brussels, 95\% (82/86) of the couples continued to at least one PGD cycle after successful genetic workup, in Maastricht this was $52 \%(43 / 82)$ and in Strasbourg 55\% (49/89). After the closure of data collection (end 2008), in Brussels, Maastricht and Strasbourg, respectively, $5 \%, 7 \%$ and $28 \%$ of the couples were about to start their first cycle.

After intake, 9\% (29/331) of the couples were rejected by the PGD centre, for example because they were considered unsuitable for IVF (3\%). In the majority of these, an anticipated reduced ovarian response was indicated by high basal levels of follicular-stimulating hormones. Other couples were rejected owing to PGD-related technical obstacles $(3 \%)$. In Maastricht, relatively more couples $(16 \%$, $16 / 100)$ were rejected compared with Brussels $(3.4 \%, 4 / 116)$ and Strasbourg $(8 \%, 9 / 115)$. A total of $18 \%(61 / 331)$ of couples refrained from PGD early or later after intake. Of the latter, one-third (19/61) refrained after achieving a spontaneous pregnancy in the meantime. Nearly $10 \%$ of the couples (32/331) were lost to follow-up. A substantial proportion of the couples refraining lost to follow-up, and rejected did complete genetic workup (52\%, 48/93).

Table 3 PGD workup and outcome after PGD intake

\begin{tabular}{|c|c|c|c|c|c|c|c|c|c|c|c|c|}
\hline & \multicolumn{3}{|c|}{ Brussels } & \multicolumn{3}{|c|}{ Maastricht } & \multicolumn{3}{|c|}{ Strasbourg } & \multicolumn{3}{|c|}{ Total } \\
\hline & Direct & Exclusion & Total & Direct & Exclusion & Total & Direct & Exclusion & Total & Direct & Exclusion & Total \\
\hline Couples for intake & 78 & 38 & 116 & 91 & 9 & 100 & 56 & 59 & 115 & 225 & 106 & 331 \\
\hline PGD workup started & 56 & 30 & 86 & 81 & $1^{a}$ & 82 & 46 & 43 & 89 & 183 & 74 & 257 \\
\hline \multicolumn{13}{|l|}{ Direct testing (CAG-repeat) } \\
\hline Informative/ & 44 & & 44 & 65 & & 65 & 38 & & 38 & 147 & & 147 \\
\hline Half informative/ & 12 & & 12 & 10 & & 10 & 8 & & 8 & 30 & & 30 \\
\hline Non-informative for normal alleles & 0 & & 0 & 2 & & 2 & 0 & & 0 & 2 & & 2 \\
\hline Linked markers & 28 & 30 & 58 & 4 & 1 & 5 & 45 & 43 & 88 & 77 & 74 & 151 \\
\hline PGD rejected by $P G D$ centre (couples) & 2 & 2 & 4 & 11 & 5 & 16 & 5 & 4 & 9 & 18 & 11 & 29 \\
\hline Unsuitable for IVF & 1 & 0 & 1 & 4 & & 4 & 3 & 1 & 4 & 8 & 1 & 9 \\
\hline Technically not feasible & 0 & 2 & 2 & 5 & & 5 & 1 & 1 & 2 & 6 & 3 & 9 \\
\hline Symptomatic HD & 1 & 0 & 1 & 2 & & 2 & & & & 3 & & 3 \\
\hline Other reason for rejecting & & 0 & & & $5^{b}$ & 5 & 1 & 2 & 3 & 1 & 7 & 8 \\
\hline Couples refraining from PGD & 15 & 4 & 19 & 32 & 3 & 35 & 3 & 4 & 7 & 50 & 11 & 61 \\
\hline Spontaneous pregnancy & 8 & 2 & 10 & 6 & & 6 & 2 & 1 & 3 & 16 & 3 & 19 \\
\hline Other reason for refraining & 7 & 2 & 9 & 26 & 3 & 29 & 1 & 3 & 4 & 34 & 8 & 42 \\
\hline Lost to follow-up & 5 & 2 & 7 & & & & 8 & 17 & 25 & 13 & 19 & 32 \\
\hline Lost FU + refraining & 20 & 6 & 26 & 32 & 3 & 35 & 11 & 21 & 32 & 63 & 30 & 93 \\
\hline Ready to start PGD (couples) & 56 & 30 & 86 & 48 & 1 & 49 & 40 & 34 & 74 & 144 & 65 & 209 \\
\hline Pending & 1 & 3 & 4 & 6 & & 6 & 15 & 10 & 25 & 22 & 13 & 35 \\
\hline Started PGD (couples) & 55 & 27 & 82 & 42 & 1 & 43 & 25 & 24 & 49 & 122 & 52 & 174 \\
\hline
\end{tabular}

an the Netherlands, one couple for exclusion PGD entered the PGD programme during a period of exception.

${ }^{b}$ Four couples asking for exclusion PGD, three men one woman at $50 \%$ risk being HD carrier, two of these couples were referred for PGD to Brussels, resulting in one pregnancy, healthy daughter. One man according to family history had max $25 \%$ risk of HD, couple asks for exclusion or non-disclosure PGD, rejected and referred for genetic counselling to nearby centre for clinical genetics. 


\section{PGD cycles}

An overview of all cycles per centre is shown in Table 4 . The mean age of woman at the start of the first cycle was 31.3 years. Overall, $53 \%$ (174/331) of couples for intake were treated (122 for direct testing and 52 for exclusion testing), 434 cycles were started and 389 cycles continued to OR. This resulted in 2.5 cycles to OR per couple in Brussels (202/82), 2.0 cycles to OR per couple (86/43) in Maastricht and $2.1(101 / 49)$ in Strasbourg. The mean number of oocytes retrieved per cycle to OR was 15.01 in Brussels, 10.82 in Maastricht and 12.42 in Strasbourg, which shows a significant increase in the number of oocytes per cycle in Brussels compared with the other two centres $(P<0.0001)$. As in the case of the number of oocytes per cycle, the number of inseminated, fertilised and biopsied embryos show significant differences as well $(P<0.0001)$.

Overall, a mean of 11.1 oocytes per OR were inseminated (4318/ 389 ) and 8.1 oocytes per cycle to OR were successfully fertilised (3133/ 389). The mean number of biopsied embryos per cycle to OR was 5.9 (2277/389). The mean number of embryos transferred per cycle was $1.6(511 / 310)$. The mean number of embryos per ET for each centre shows the opposite effect: 1.56 in Brussels, 1.77 in Maastricht and 1.72 in Strasbourg (significantly less embryos per ET in Brussels compared with Maastricht and Strasbourg: $P=0.0048$ ).

\section{Pregnancy outcome and children}

In total, 105 positive hCG tests occurred ( 84 women), resulting in 84 clinical pregnancies. Of the latter, five were lost in the first trimester. Detailed information on pregnancies and babies per centre are listed in Supplementary Tables S1 and S2. A summary of cycles, pregnancies and babies is shown in Table 5 . The clinical pregnancy rate was $21.6 \%$ per cycle to OR and $27.1 \%$ per transfer. The delivery rates per OR were $19.8 \%$, and per embryo transfer $24.8 \%$. The overall delivery rate $(\geq 1$ delivery) of couples starting $\geq 1$ PGD cycle was $37.4 \%$ (65/174). The pregnancy and delivery rates at the three centres did not show any significant differences. The 77 deliveries (65 couples) resulted in the birth of 90 children (65 singletons, 11 pairs of twins and one set of triplets). PND to confirm PGD results was performed more frequently in Brussels (41\%, 19/46 of clinical pregnancies) than in Maastricht $(10 \%, 2 / 21)$ and Strasbourg $(0 \%)$.

\section{PGD uptake}

To get an impression of the uptake of PGD in the three countries, the couples for PGD intake can be compared with the population at risk for $\mathrm{HD}^{28}$ at a reproductive age (Table 6). According to the literature, the prevalence of $\mathrm{HD}$ is similar in the three countries (7.5 per $100000){ }^{3,4}$ The population with a $50 \%$ risk of being an HD carrier was calculated according to Conneally: ${ }^{28}$ five times the prevalence of HD. The reproductive age group of at-risk (presymptomatic) persons was estimated to be half the total at-risk population, since the average age of onset is 30-40 years and the reproductive age starts around 15 to 20 years. Over a period of 10 years, the uptake of PGD for HD in Belgium was $8.5 \%$, in the Netherlands the uptake was $5.8 \%$ and in France $3.7 \%$.

\section{DISCUSSION}

With an overall delivery rate of $37.4 \%$, we conclude that PGD has become a successful reproductive option for couples at risk of transmitting HD.

\section{PGD outcome}

The success rates of the three PGD centres are similar and match international data on pregnancy rates in PGD., 5,11,29-32 The mean age of woman at the beginning of the first cycle (31.3 years), as well as the delivery rates per OR $(19.8 \%)$ and per ET $(24.8 \%)$, are similar to those for PGD for HD reported in the ESHRE PGD data collection X (mean age of woman: 32.0 years; delivery rate per OR: $19.8 \%$ and per ET: $23.6 \%) .{ }^{30}$ The increased number of oocytes per cycle in Brussels compensated for the reduced number of embryos per ET in Brussels (single ET law since 2003), and did not result in an increased pregnancy rate.

So far, no misdiagnosis has been reported. However, we realise that the choice of PGD to avoid TOP, the late onset of HD and the limited risk of misdiagnosis have led to a low uptake of control PND (21 tests/ 84 clinical PGD pregnancies) with a predominance of Belgian couples. ${ }^{14,15}$ We presume that counselling differences may have contributed to the different numbers of control PND in the three centres. Moreover, presymptomatic testing for HD in newborns or older children is not recommended by the European Society of Human Genetics. ${ }^{33}$ In consequence, the chances of tracing a misdiagnosis after PGD for HD within two or three decades will be very limited. ${ }^{14}$

\section{Reproductive history}

In Strasbourg, significantly more couples (51\%) opted for exclusion PGD than in Brussels (33\%; $P=0.0065)$. In Australia, the proportion of exclusion PGD was 33\%, which is comparable to Brussels. ${ }^{31,32}$ One might speculate that the increased interest in exclusion PGD in France is due to the relatively low uptake of presymptomatic testing for HD in France compared with Belgium and the Netherlands. ${ }^{34}$ The position of the French Huntington Associations in favour of exclusion testing, coupled with counselling differences, may contribute to this difference. Another explanation might be that, since the first application of exclusion PGD, exclusion PND was no longer offered in France (personal communication, Moutou). The reluctance of couples to face PND and TOP, as well as the reluctance of care providers to offer (exclusion) PND for HD, may also be a reason for this reduction. A remarkable finding was that in Strasbourg there were eight couples who had a TOP without PND, compared with one in Maastricht and one in Brussels. The reproductive histories of couples opting for PGD exclusion testing showed relatively fewer pregnancies and significantly fewer pregnancy terminations after PND $(P=0.0027)$ compared with couples opting for PGD with direct testing. We conclude that couples opting for exclusion testing are more likely to choose PGD, whereas couples opting for direct testing more frequently choose PGD after a history of TOP. This may support the view that prenatal exclusion testing with subsequent TOP is even more difficult for at-risk couples than PND with subsequent TOP for definite HD carriers. After exclusion $\mathrm{PND}, 50 \%$ of the terminated pregnancies will in fact be unaffected, whereas after direct PND all terminated pregnancies will be truly affected.

Our study shows an exact 50:50 male:female ratio $(n=331)$ with respect to the $\mathrm{HD}$ carriers or at-risk persons at PGD intake. This ratio is somewhat different from the 40:60 (male:female) ratio reported for couples opting for presymptomatic testing, ${ }^{35-39}$ and to the $40: 60$ distribution among the couples opting for PND. ${ }^{34,36,40,41}$ Whether these differences are true or biased, perhaps because of small sample sizes, remains to be elucidated.

\section{PGD approach}

During the period covered by this study, PGD procedures for each centre evolved from simplex PCR for the CAG repeat length to multiplex PCR in which several microsatellite markers flanking the HTT gene are combined alone or with the CAG repeat. With the increasing number of markers applied, the chances of couples being 


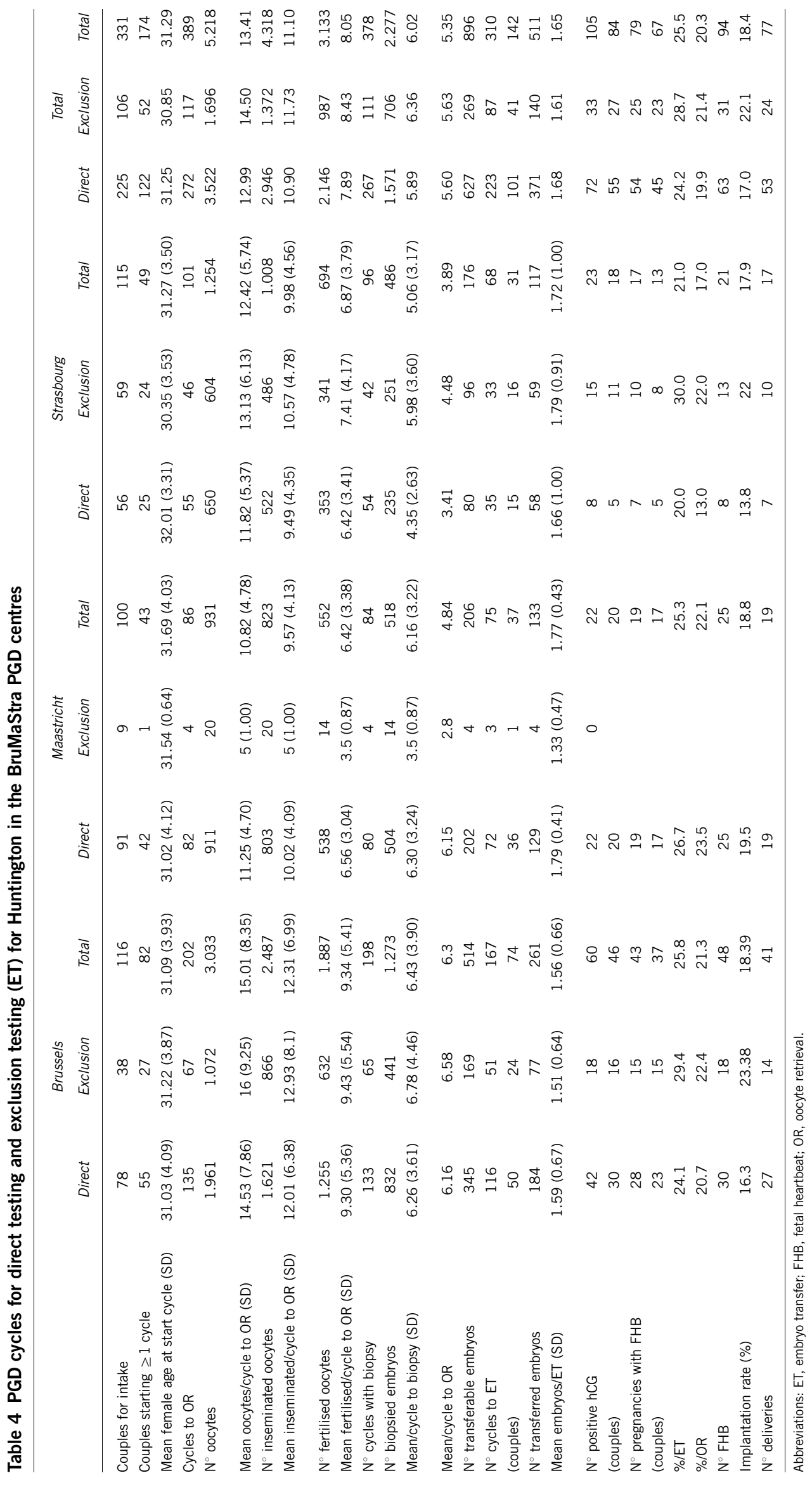


Table 5 Summary of cycles, pregnancies and babies

\begin{tabular}{|c|c|c|c|c|c|c|c|c|c|c|c|c|}
\hline & \multicolumn{3}{|c|}{ Brussels } & \multicolumn{3}{|c|}{ Maastricht } & \multicolumn{3}{|c|}{ Strasbourg } & \multicolumn{3}{|c|}{ Total } \\
\hline Intakes & 78 & 38 & 116 & 91 & 9 & 100 & 56 & 59 & 115 & 225 & 106 & 331 \\
\hline Cycles to ET (couples) & $116(50)$ & $51(24)$ & $167(74)$ & $72(36)$ & $3(1)$ & $75(37)$ & $35(15)$ & $33(16)$ & $68(31)$ & $223(101)$ & $87(41)$ & $310(142)$ \\
\hline Clinical pregnancies (couples) & $31(25)$ & $15(14)$ & 46 (39) & $21(19)$ & 0 & $21(19)$ & $7(5)$ & $10(8)$ & $17(13)$ & $59(49)$ & $25(22)$ & $84(71)$ \\
\hline Clinical pregnancy rate/cycle to ET & $24.1 \%$ & $29.4 \%$ & $25.7 \%$ & $26.4 \%$ & & $25.7 \%$ & $20.0 \%$ & $30.3 \%$ & $25.0 \%$ & $24.2 \%$ & $29.1 \%$ & $25.6 \%$ \\
\hline Delivery rate/cycle to OR & $20.0 \%$ & $20.9 \%$ & $20.3 \%$ & $23.2 \%$ & $0 \%$ & $22.1 \%$ & $12.7 \%$ & $21.7 \%$ & $16.8 \%$ & $19.5 \%$ & $20.5 \%$ & $19.8 \%$ \\
\hline Delivery rate/cycle to ET & $23.3 \%$ & $27.5 \%$ & $24.6 \%$ & $26.4 \%$ & $0 \%$ & $25.3 \%$ & $20.0 \%$ & $30.3 \%$ & $25.0 \%$ & $23.8 \%$ & $27.6 \%$ & $24.8 \%$ \\
\hline Delivery rate couples started ${ }^{a}$ & $40.0 \%$ & $48.1 \%$ & $42.7 \%$ & $40.5 \%$ & & $39.5 \%$ & $20.0 \%$ & $33.3 \%$ & $26.5 \%$ & $36.1 \%$ & $40.4 \%$ & $37.4 \%$ \\
\hline
\end{tabular}

Abbreviations: $\mathrm{ET}$, embryo transfer; OR, oocyte retrieval.

${ }^{a}$ Couples with $\geq 1$ baby/couples started.

Table 6 Uptake PGD for HD in the three countries

\begin{tabular}{|c|c|c|c|c|c|c|c|c|c|}
\hline & $\begin{array}{c}\text { Population } \\
\text { size }\end{array}$ & $\begin{array}{l}\text { Reproductive } \\
\text { population at } \\
\text { risk for } H D^{a}\end{array}$ & $\begin{array}{c}P G D \\
\text { intakes }\end{array}$ & Years & $\begin{array}{c}\text { PGD intakes/ } \\
\text { at-risk } \\
\text { population }\end{array}$ & $\begin{array}{c}\text { PGD intakes/ } \\
\text { yearlat-risk } \\
\text { population }\end{array}$ & $\begin{array}{c}P G D \\
\text { started }\end{array}$ & $\begin{array}{c}\text { PGD started/ } \\
\text { at-risk } \\
\text { population }\end{array}$ & $\begin{array}{c}\text { 10-Year uptake: } \\
\text { PGD started/ } \\
10 \text { yearlat-risk } \\
\text { population }\end{array}$ \\
\hline Belgium & 11 Million & 412.5 & $71^{\mathrm{b}}$ & 14 (1995-2008) & $17.2 \%$ & $1.23 \%$ & $49^{c}$ & $11.9 \%$ & $8.5 \%$ \\
\hline The Netherlands & 16 Million & 600 & 100 & 14 (1995-2008) & $16.7 \%$ & $1.19 \%$ & $49^{d}$ & $8.17 \%$ & $5.8 \%$ \\
\hline France & 63 Million & 2362.5 & $142^{\mathrm{e}}$ & 9 (2000-2008) & $6.01 \%$ & $0.67 \%$ & $79^{f}$ & $3.34 \%$ & $3.7 \%$ \\
\hline
\end{tabular}

aReproductive population was estimated approximately half of the at-risk population; at-risk population according to Conneally: five times the number of affected persons with a mean prevalence of 7.5 per 100000 citizens.

bIn Brussels, 71 of all 116 intakes were Belgian couples.

In Brussels, 49 of all 86 couples who started PGD were Belgian couples.

dAll of the 6 pending couples in the Netherlands continued to start PGD after data collection; making a total of 49 started couples.

eTwo PGD centres in France perform PGD for HD: 115 intakes in Strasbourg and 27 intakes in Montpellier.

$\mathrm{f}$ In France, 61 couples started PGD for HD in Strasbourg and 18 in Montpellier.

unsuitable for PGD because of non-informativity have decreased over the years. ${ }^{5-7}$ In addition, this combined approach improves the reliability of the proposed tests.

The number of couples rejected after PGD counselling is significantly higher in Maastricht (16\%) than in Brussels (3.4\%) and Strasbourg (8\%), even after subtracting the exclusion PGD requests in Maastricht $(12 \%, 11 / 91)$. One causative difference is that before the introduction of marker testing, half-informative couples were rejected in Maastricht, whereas they were treated in Brussels. In Strasbourg, PGD was combined with linkage analyses for all half-informative couples, from the beginning. Maastricht introduced marker testing for HD 2 years later (2006) than Brussels and Strasbourg (2004). ${ }^{5,6}$ Moreover, the inclusion criteria for IVF in Maastricht are stricter than in Brussels and Strasbourg. A considerable proportion of couples (18\%) refrained from PGD after intake, and 10\% of the couples were lost to follow-up after intake. The relatively high number of couples lost to follow-up in France could be because of the distances the couples had to travel to the PGD centre in Strasbourg, as well as because of the long delays between intake and PGD.

\section{Uptake}

France had a lower uptake of PND between 1993 and 1998 (0.12. PND per million) compared with other European countries studied (Belgium 2.9 PND per million, The Netherlands 5.7 PND per million). ${ }^{34}$ Calculating the PGD uptake, we used the 1:5 (HD prevalence:50\% HD risk) ratio proposed by Conneally. ${ }^{28}$
As the PGD population consists of both couples at a 50\% risk and confirmed presymptomatic carriers, we did not correct for the presymptomatic HD carriers as recently proposed. ${ }^{42}$ The 10-year uptake of PGD for HD in Belgium in the at-risk population in the reproductive age was $8.5 \%$, in the Netherlands it was $5.8 \%$ and in France $3.7 \%$. In the first few years after the implementation of PGD, the yearly data showed some fluctuation, but after a gradual increase the yearly implementation of PGD is now showing more stability. If we consider the proportion of exclusion testing in Brussels and the proportion in Strasbourg, the uptake of direct testing in Brussels and the Netherlands shows great similarity. In addition, the uptake of exclusion PGD in France and Belgium seems quite similar. The limitations of our uptake calculations are the limited period of study and the time lapse between the intake of PGD couples and their first cycle, making it difficult to define the right period. Furthermore, many refraining couples are still of reproductive age and might still reconsider starting PGD. In a previous study on heterogeneous PGD candidates, we observed that $5 \%$ of the couples actually starting PGD had refrained from PGD previously. ${ }^{43}$ For a more accurate calculation of the PGD uptake in the future, a longer period should be studied excluding the first years of implementation of PGD.

\section{CONCLUSION}

We conclude that in the past two decades PGD has become an appropriate reproductive option for couples at risk of transmitting HD. For the relatively large number of at-risk persons who decide to 
remain uninformed about their own carrier status, exclusion PND or exclusion PGD are options leading to biological offspring free from HD. The availability of exclusion PGD for countries where it is not yet permitted has to be reconsidered, as it is clear that this procedure supplies a need. Finally, the importance of proper genetic and reproductive counselling for all couples considering PND or PGD should be emphasised.

\section{CONFLICT OF INTEREST}

The authors declare no conflict of interest.

1 Bates G, Harper P, Jones L: Huntington's Disease. New York: Oxford University Press, 2002

2 MacDonald ME, Ambrose CM, Duyao MP et al: HDCRG: a novel gene containing a trinucleotide repeat that is expanded and unstable on Huntington's disease chromosomes. Cell 1993; 72: 971-983.

3 Novak MJ, Tabrizi SJ: Huntington's disease. BMJ 2010; 340: c3109.

4 Roos RA: Huntington's disease: a clinical review. Orphanet J Rare Dis 2010; 5: 40.

5 Moutou C, Gardes N, Viville S: New tools for preimplantation genetic diagnosis of Huntington's disease and their clinical applications. Eur J Hum Genet 2004; 12 1007-1014.

6 Sermon K, De Rijcke M, Lissens W et al: Preimplantation genetic diagnosis for Huntington's disease with exclusion testing. Eur J Hum Genet 2002; 10: 591-598.

7 Sermon K, Goossens V, Seneca S et al: Preimplantation diagnosis for Huntington's disease (HD): clinical application and analysis of the HD expansion in affected embryos. Prenat Diagn 1998; 18: 1427-1436.

8 Sermon K, Seneca S, De Rycke M et al: PGD in the lab for triplet repeat diseases - myotonic dystrophy, Huntington's disease and Fragile-X syndrome. Mol Cell Endocrinol 2001; 183 Suppl 1: S77-S85.

9 Harper PS, Sarfarazi M: Genetic prediction and family structure in Huntington's chorea. BMJ (Clin Res Ed) 1985; 290: 1929-1931.

10 Schulman JD, Black SH, Handyside A, Nance WE: Preimplantation genetic testing for Huntington disease and certain other dominantly inherited disorders. Clin Genet 1996; 49: 57-58.

11 Stern HJ, Harton GL, Sisson ME et al: Non-disclosing preimplantation genetic diagnosis for Huntington disease. Prenat Diagn 2002; 22: 503-507.

12 Braude PR, De Wert GM, Evers-Kiebooms G, Pettigrew RA, Geraedts JP: Non-disclosure preimplantation genetic diagnosis for Huntington's disease: practical and ethical dilemmas. Prenat Diagn 1998; 18: 1422-1426.

13 Evers-Kiebooms G, Zoeteweij M, Harper PS: Prenatal Testing for Late-Onset Neurogenetic Diseases. Oxford: BIOS Scientific Publishers Ltd, 2002.

14 Dreesen J, Drusedau M, Smeets $\mathrm{H}$ et al: Validation of preimplantation genetic diagnosis by PCR analysis: genotype comparison of the blastomere and corresponding embryo, implications for clinical practice. Mol Hum Reprod 2008; 14: 573-579.

15 Wilton L, Thornhill A, Traeger-Synodinos J, Sermon KD, Harper JC: The causes of misdiagnosis and adverse outcomes in PGD. Hum Reprod 2009; 24: 1221-1228.

16 Gianaroli L, Plachot M, van Kooij $\mathrm{R}$ et al: ESHRE guidelines for good practice in IVF laboratories. Committee of the Special Interest Group on Embryology of the European Society of Human Reproduction and Embryology. Hum Reprod 2000; 15: 2241-2246.

17 Thornhill AR, de Die-Smulders CE, Geraedts JP et al: ESHRE PGD consortium 'best practice guidelines for clinical preimplantation genetic diagnosis (PGD) and preimplantation genetic screening (PGS)'. Hum Reprod 2005; 20: 35-48.

18 Vandervorst $\mathrm{M}$, Liebaers I, Sermon $\mathrm{K}$ et al: Successful preimplantation genetic diagnosis is related to the number of available cumulus-oocyte complexes. Hum Reprod 1998; 13: 3169-3176.

19 Devroey P, Van Steirteghem A: A review of ten years experience of ICSI. Hum Reprod Update 2004; 10: 19-28.

20 De Vos A, Van Steirteghem A: Aspects of biopsy procedures prior to preimplantation genetic diagnosis. Prenat Diagn 2001; 21: 767-780.
21 Goossens V, De Rycke M, De Vos A et al: Diagnostic efficiency, embryonic development and clinical outcome after the biopsy of one or two blastomeres for preimplantation genetic diagnosis. Hum Reprod 2008; 23: 481-492.

22 Van Landuyt L, De Vos A, Joris H, Verheyen G, Devroey P, Van Steirteghem A: Blastocyst formation in in vitro fertilization versus intracytoplasmic sperm injection cycles: influence of the fertilization procedure. Fertil Steril 2005; 83: 1397-1403.

23 Sermon K, Van Steirteghem A, Liebaers I: Preimplantation genetic diagnosis. Lancet 2004; 363: 1633-1641.

24 Zegers-Hochschild F, Adamson GD, de Mouzon J et al: The International Committee for Monitoring Assisted Reproductive Technology (ICMART) and the World Health Organization (WHO) Revised Glossary on ART Terminology, 2009. Hum Reprod 2009; 24: 2683-2687.

25 Bonduelle M, Liebaers I, Deketelaere V et al: Neonatal data on a cohort of 2889 infants born after ICSI (1991-1999) and of 2995 infants born after IVF (1983-1999). Hum Reprod 2002; 17: 671-694.

26 Wet betreffende medisch begeleide voortplanting en de bestemming van de overtollige embryo's en gameten (Law concerning assisted reproduction and the handeling of surpluss embryos and gametes). Belgisch Staatsblad 2007; 38575-38586.

27 Regeling van de staatssecretaris van Volksgezondheid, Welzijn en Sport van 16 februari 2009, nr. CZ-TSZ-2912089, houdende regels ten aanzien van preïmplantatie genetische diagnostiek (PGD) (Regeling preïmplantatie genetische diagnostiek) (Regulations of the State Secretary of Health on the rules concerning PGD). Staatscourant 2009; $1-12$.

28 Conneally PM: Huntington disease: genetics and epidemiology. Am J Hum Genet 1984; 36: 506-526

29 Decruyenaere M, Evers-Kiebooms G, Boogaerts A et al: The complexity of reproductive decision-making in asymptomatic carriers of the Huntington mutation. Eur J Hum Genet 2007; 15: 453-462.

30 Harper JC, Coonen E, De Rycke M et al: ESHRE PGD consortium data collection X: cycles from January to December 2007 with pregnancy follow-up to October 2008. Hum Reprod 2010; 25: 2685-2707.

31 Jasper MJ, Hu DG, Liebelt J et al: Singleton births after routine preimplantation genetic diagnosis using exclusion testing (D4S43 and D4S126) for Huntington's disease. Fertil Steril 2006; 85: 597-602.

32 Tassicker RJ, Marshall PK, Liebeck TA, Keville MA, Singaram BM, Richards FH: Predictive and prenatal testing for Huntington Disease in Australia: results and challenges encountered during a 10-year period (1994-2003). Clin Genet 2006; 70: 480-489.

33 Borry P, Evers-Kiebooms G, Cornel MC, Clarke A, Dierickx K: Genetic testing in asymptomatic minors: background considerations towards ESHG recommendations. Eur J Hum Genet 2009; 17: 711-719.

34 Simpson SA, Zoeteweij MW, Nys K et al: Prenatal testing for Huntington's disease: a European collaborative study. Eur J Hum Genet 2002; 10: 689-693.

35 Craufurd D, Dodge A, Kerzin-Storrar L, Harris R: Uptake of presymptomatic predictive testing for Huntington's disease. Lancet 1989; 2: 603-605.

36 Creighton S, Almqvist EW, MacGregor D et al: Predictive, pre-natal and diagnostic genetic testing for Huntington's disease: the experience in Canada from 1987 to 2000. Clin Genet 2003; 63: 462-475.

37 Evers-Kiebooms G, Nys K, Harper P et al: Predictive DNA-testing for Huntington's disease and reproductive decision making: a European collaborative study. Eur J Hum Genet 2002; 10: 167-176.

38 Harper PS, Lim C, Craufurd D: Ten years of presymptomatic testing for Huntington's disease: the experience of the UK Huntington's disease prediction consortium. J Med Genet 2000; 37: 567-571.

39 Maat-Kievit A, Vegter-van der Vlis M, Zoeteweij M, Losekoot M, van Haeringen A, Roos R: Paradox of a better test for Huntington's disease. J Neurol Neurosurg Psychiatry 2000; 69: 579-583.

40 Adam S, Wiggins S, Whyte P et al: Five year study of prenatal testing for Huntington's disease: demand, attitudes, and psychological assessment. J Med Genet 1993; 30: 549-556.

41 Maat-Kievit A, Vegter-van der Vlis M, Zoeteweij $M$ et al: Experience in prenatal testing for Huntington's disease in the Netherlands: procedures, results and guidelines (1987-1997). Prenat Diagn 1999; 19: 450-457.

42 Tassicker RJ, Teltscher B, Trembath MK et al: Problems assessing uptake of Huntington disease predictive testing and a proposed solution. Eur J Hum Genet 2009; 17: 66-70.

43 van Rij MC, Gielen M, Lulofs R et al: Profiles and motives for PGD: a prospective cohort study of couples referred for PGD in the Netherlands. Hum Reprod 2011; 26: 1826-1835.

Supplementary Information accompanies the paper on European Journal of Human Genetics website (http://www.nature.com/ejhg) 